(c) All rights are reserved by Michelle Lai et al.

\title{
Perioperative Depression in Older Patients after Hip Fracture
}

Keywords: Hip fractures; Depression; Dementia; Perioperative care; Age

\section{Abstract}

Aim: Depression in patients after hip fracture has adverse effects on patient outcomes. This study aimed to identify the prevalence of perioperative depression and the risk factors which predispose patients undergoing emergency hip surgery to perioperative depression.

Methods: A cross-sectional study was conducted in hip fracture survivors in an orthogeriatric unit in Westem Australia, from 2005 to 2008. Patients were categorized as depressed if Geriatric Depression Scale (GDS) score was five or above. Linear regression was used to analyze the association between age and GDS. Modifying effect of dementia was examined using likelihood ratio test.

Results: Depression was present in $18.3 \%$ of 1127 patients within two weeks after hip fracture. Mean age was 81.2 years. Prevalence of perioperative depression was highest in the old-old (24.1\%) and in patients with pre-existing dementia (64.8\%). Advancing age, prefracture institutionalization, use of gait aids, poor physical status, and dementia were associated with higher GDS scores, but not gender or perioperative delirium. The association between increasing depressive symptoms and advancing age was significant in patients without dementia but not in patients with dementia.

Conclusions: Depressive symptoms were common during perioperative care for emergency hip surgery. Depression was highly prevalent in patients with dementia afterhip fracture regardless of their age. Pre-morbid patient factors may help to identify those patients at risk for depression and should be addressed to optimize rehabilitation partic ipation and outcomes.

\section{Introduction}

Hip fracture is a disabling medical event in older people and poses a significant risk for developing depression in late life [1]. Depressive symptoms among older patients following hip fracture are common and prevalence rates from 9 to $47 \%$ have been reported [2] Perioperative depression interferes with functional recovery [3], and is associated with greater physical disability [4,5], institutionalization [5] and higher mortality [6-8]. It is, therefore, important to identify patients at high risk of depression during the perioperative period.

Hip fracture is a clear stressor precipitating the onset of depression. During the perioperative period, patients may suffer from pain, sleep disturbances, immobilization, unpredictable prognosis and functional disability [9]. The risk for developing depression is particularly high in the first 2 weeks after hip fracture [10]. The detection of depressive symptoms allows for early effective nonpharmacological interventions during the rehabilitation period to optimize patient outcomes [11].

Age, gender, pre-morbid functional status, pre-existing comorbidities, residential status, poor cognition and delirium all can affect patient outcomes after hip fracture [4,12-15]. The co-occurrence of depression and pre-exisiting dementia in these patients has an adverse effect on mobility, functional outcomes and survival [4,7]. Understanding relevant patient factors associated with depression would help to identify patients at risk of depression after hip fracture.

\section{Journal of \\ Geriatrics and Palliative Care}

\author{
Michelle Mei Yee Lai ${ }^{1,2,3 *}$, Noreen Mughal ${ }^{4}$ \\ Christopher Fong ${ }^{1,2}$ and Stephen Fenner ${ }^{5}$ \\ ${ }^{1}$ Eastern Health Clinical School, Monash University, Australia \\ ${ }^{2}$ Caulfield Hospital, Australia \\ ${ }^{3}$ National Ageing Research Institute, Australia \\ ${ }^{4}$ Department of Geriatric Medicine, Royal Perth Hospital, Australia \\ ${ }^{5}$ Department of Psychiatry, Royal Perth Hospital, Australia

\section{Address for Correspondence} \\ Michelle Lai, Eastern Health Clinical School, Monash University, \\ Level 3, 5 Arnold Street, Box Hill VIC 3128, Australia, Email: \\ michellemylai@gmail.com \\ Copyright: (c) 2013 Lai MM, et al. This is an open access article \\ distributed under the Creative Commons Attribution License, which \\ permits unrestricted use, distribution, and reproduction in any medium, \\ provided the original work is properly cited. \\ Submission: 08 September 2013 \\ Accepted: 19 November 2013 \\ Published: 25 November 2013
}

This study sought to 1) determine the prevalence of depressive symptoms in the orthogeriatric setting, 2) examine the potential factors associated with depressive symptoms, and 3) determine whether dementia modified the association between depression and potential factors.

\section{Methods}

A cross-sectional study was conducted on 1127 hip fracture survivors in an orthogeriatric unit at Royal Perth Hospital in Western Australia, from 2005 to 2008. Patients were aged 50 years or older and received emergency surgery for hip fracture. Geriatric Depression Scale (GDS-15) were performed as part of comprehensive assessments for all older patients admitted to the unit [16]. Patients were excluded if they were unable to complete assessments using the GDS. Most exclusions were due to severe cognitive impairment or delirium with poor recovery within the first two weeks of admission.

Data were obtained from an administrative dataset, which was prospectively collected and maintained by a fracture nurse coordinator. The following patient factors were analyzed: age, gender, pre-fracture residence, mobility, the American Society of Anesthesiologists (ASA) physical status score, pre-existing dementia and perioperative delirium.

\section{Measurements}

GDS-15 is a validated 15-item self-report instrument designed to evaluate symptomatology of depression in older patients (score $0-15$, with a lower score indicating a better mood rating) [16]. The lack of somatic symptoms enquiry in GDS-15 is desirable for screening depression after hip fracture, as pain and other physical symptoms are often present as a result of musculoskeletal injury [16]. Medical doctors performed GDS-15 on all older patients admitted to the orthogeriatric unit within the first two weeks of hospitalization after a hip fracture. A GDS-15 cutoff of five or above out of 15 was defined as significant depressive symptoms. This cutoff has previously been shown to have adequate sensitivity and specificity to screen for major depression, as defined by DSM-IV criteria [16]. The ASA score estimates patients' physical status and the scale has been shown to correlate with operative risk (score 1-5, with higher score indicating 
Citation: Lai MM, Mughal N, Fong C, Fenner S. Perioperative Depression in Older Patients after Hip Fracture. J Geriatrics Palliative Care 2013;1(1): 4.

ISSN: 2373-1133

worse physical health) [17]. The older patient is defined as having dementia if the diagnosis was previously made by a clinician prior to the admission for fracture. The presence of delirium was assessed by a Geriatrician during the perioperative period using the Confusion Assessment Method (CAM) [18]. The perioperative period was defined as the period in the first two weeks of hospitalization for hip fracture in this study.

\section{Statistical Analysis}

All data were analyzed using Stata version 11 (StataCorp LP, College Station TX, USA). The normal distribution of continuous variables and the assumptions underlying linear associations between patient factors and GDS were confirmed by visual inspection. Prevalence of significant depressive symptoms was examined in three age categories: $<74$ years, $75-84$ years and $\geq 85$ years. We used a trend test to examine the descriptive statistics across age groups. Univariate associations were examined between age and GDS. Linear regression model was used to adjust for confounder variables. Interactions between GDS and dementia were examined using a likelihood ratio test.

\section{Results}

A total of 1136 patients aged 50 years or older received an operation for a hip fracture during the study period. GDS-15 was completed in 1127 patients with 809 female and 318 male patients. Mean age was $81.2 \pm 9.5$ years. All patients who had completed the GDS-15 were included in the analysis. Mean GDS-15 score was similar in women and men $(2.21 \pm 1.74 \mathrm{v} 2.17 \pm 1.77, \mathrm{P}>0.05)$.

\section{Prevalence of depressive symptoms}

Depression was present in $17.9 \%$ of 809 women and $18.4 \%$ of 318 men within the two weeks after hip fracture. Prevalence of depression was the highest in the age group of $\geq 85$ years $(24.1 \%)$ and in patients with dementia $(64.8 \%)$. The prevalence of clinical depression with a high GDS score increased with advancing age groups in both genders (all $\mathrm{P}<0.005$ for trend) (Table 1 ).

\section{Patient factors and GDS}

Advancing age, premorbid institutionalization, pre-fracture use of a gait aid, poor ASA score, dementia and perioperative delirium were associated with a higher score in GDS (all $\mathrm{P}<0.05$ ). No association was found between gender and GDS-15 score (Table 2). GDS score increased by 0.01 point for each year increase in age in all patients (adjusted beta $=0.01, \mathrm{P}=0.03$ ).

\section{Modifying effect of dementia on GDS and other factors}

The modifying effect of a pre-existing clinical diagnosis of dementia on the association between age and GDS was examined, after controlling for other factors. Depressive symptoms were significantly associated with advancing age in patients who did not have pre-existing dementia $(\mathrm{r}=0.19, \mathrm{P}<0.001)$, but not in patients with dementia $(\mathrm{r}=-0.06, \mathrm{P}=0.36)($ LR test $\operatorname{chi} 2(1)=8.92, \mathrm{P}<0.01)$ (Figure 1$)$. Dementia did not modify the associations between GDS-15 scores and the other studied factors.

\section{Discussion}

This study showed that approximately $18 \%$ of patients reported depressive symptoms immediately after hip fracture. This figure was in the middle of the prevalence range noted in other similar studies
Table 1: Prevalence of depression in 1127 patients after hip fracture by age and gender, using GDS-15.

\begin{tabular}{|l|l|l|l|}
\hline Variables & $\begin{array}{l}\text { Men } \\
(\mathbf{n = 3 1 8})\end{array}$ & $\begin{array}{l}\text { Women } \\
(\mathbf{n = 8 0 9 )}\end{array}$ & $\begin{array}{l}\text { All } \\
(\mathbf{n = 1 1 2 7})\end{array}$ \\
\hline GDS $\geq 5, \mathrm{n}(\%)$ & $57(17.9)$ & $149(18.4)$ & $206(18.3)$ \\
\hline Age Group (years) & & & \\
\hline$<75, \mathrm{n}(\%)$ & $10(10.1)$ & $7(4.9)$ & $17(7.1)$ \\
\hline $75-84, \mathrm{n}(\%)$ & $19(16.6)$ & $57(18.8)$ & $76(18.2)$ \\
\hline$\geq 85, \mathrm{n}(\%)$ & $28(26.7)$ & $85(23.4)$ & $113(24.1)$ \\
\hline P value for trend & 0.002 & $<0.001$ & $<0.001$ \\
\hline
\end{tabular}

GDS, Geriatric Depression Scale

Comparisons between men and women across all age groups were insignificant ${ }^{\dagger}$ Chi-square linear by linear association

Table 2: Multiple linear regression model of age on GDS-15, within two weeks after hip fracture in 1127 older adults.

\begin{tabular}{|l|c|c|c|c|}
\hline $\begin{array}{l}\text { GDS (0-15) Patient } \\
\text { Factors }\end{array}$ & Crude $\boldsymbol{\beta}^{+}(\mathbf{9 5 \%} \mathbf{C l})$ & $\mathbf{P}$ & $\begin{array}{c}\text { Adjusted } \boldsymbol{\beta}^{+} \mathbf{( 9 5 \%} \\
\mathbf{C l})\end{array}$ & $\mathbf{P}$ \\
\hline Age (years) & $0.42(0.32,0.52)$ & $<0.001$ & $0.10(0.01,0.20)$ & 0.03 \\
\hline Male & $0.02(-0.08,0.12)$ & 0.36 & $-0.03(-0.12,0.05)$ & 0.48 \\
\hline $\begin{array}{l}\text { Residential Care } \\
\text { (yes v no) }\end{array}$ & $0.66(0.57,0.76)$ & $<0.001$ & $0.18(0.08-0.27)$ & $<0.001$ \\
\hline $\begin{array}{l}\text { Use of gait aid (yes } \\
\text { v no) }\end{array}$ & $0.38(0.28,0.48)$ & $<0.01$ & $0.12(0.03,0.21)$ & 0.01 \\
\hline $\begin{array}{l}\text { ASA physical } \\
\text { status (1-5) }\end{array}$ & $0.38(0.27,0.50)$ & $<0.001$ & $0.17(0.08,0.26)$ & $<0.001$ \\
\hline $\begin{array}{l}\text { Dementia history } \\
\text { (yes v no) }\end{array}$ & $1.14(1.07,1.22)$ & $<0.001$ & $1.03(0.94,1.12)$ & $<0.001$ \\
\hline Delirium (yes v no) & $-2.69(-3.70,-1.68)$ & $<0.001$ & $-0.37(-1.24,0.50)$ & 0.40 \\
\hline
\end{tabular}

GDS, Geriatric Depression Scale; ASA, American Society of Anesthesiologists; $\mathrm{Cl}$, confidence interval

${ }^{\dagger} \beta$ represented per standard deviation change

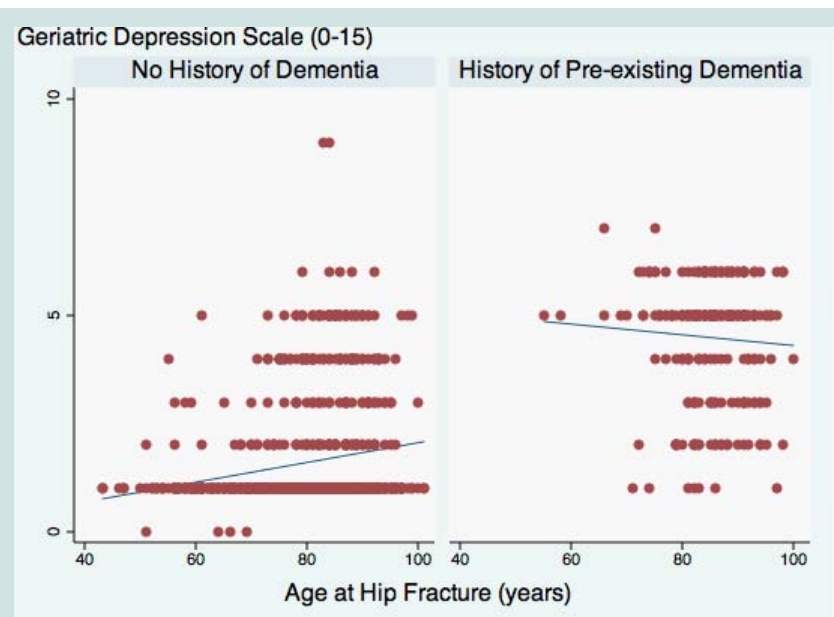

Figure 1: Relationship of age and depression score in 1127 patients with emergency hip fracture surgery with and without dementia.

$[2,9,19]$. Prevalence of depression was highest in the oldest age group and in those with dementia regardless of the gender.

In a previous study involving 146 elderly inpatients following hip fracture, the co-occurrence of depression and cognitive impairment hampered patients' improvement in ambulatory and functional status, compared to the presence of cognitive impairment alone [4]. 
Citation: Lai MM, Mughal N, Fong C, Fenner S. Perioperative Depression in Older Patients after Hip Fracture. J Geriatrics Palliative Care 2013;1(1): 4.

In another study, patients had a lower 12-month survival if they had both dementia and depression compared to those with dementia alone [7]. Our study added to the evidence that the association between depression and advancing age was observed in patients after hip fracture but not in those with dementia. The presence of dementia is a strong risk factor for perioperative depression in older patients after hip fracture and should prompt clinicians to assess for depression regardless of a patients' age.

The GDS-15 was performed within two weeks of admission in this study. It should be noted that our study is not designed to detect Major Depressive Disorder (MDD), which requires a two-week history of symptoms for the diagnosis. The short 15 -item GDS is commonly used in screening for late-life depression in a multitude of settings $[11,14,20]$. During acute admission for orthorgeriatric care, longer diagnostic assessments, such as the Structured Clinical Interview for DSM-IV (SCID), are not routinely performed. The GDS-15 is an easy to administer assessment tool that is used to identify those patients at risk of depression for further assessment. This instrument is designed to exclude certain somatic symptoms. Therefore, it was suitable to use in our study population with physical symptoms due to hip fracture and perioperative medical illness [14]. Furthermore, its simple response format facilitated response in individuals who were cognitively impaired or recently recovered from delirium [20].

GDS as a screening tool in this study has a shortcoming; it would not be able to differentiate reactive depression from chronic depression. Depressive symptoms during this early perioperative period after hip fracture may not equate clinical depression, but possibly be due to delirium, an adjustment reaction or simply not accurately reported in those older patients with dementia [9].

This study was designed to assess patients immediately after their hip fracture, because the risk for developing depression was shown to be the highest in the first 10 weeks, and predominantly in the first two weeks [9]. It is important to note that this 'risk window' may be different from other conditions, for instance, the risk of depression is highest 3-6 months after a stroke [21]. Depressive symptoms compromise functional rehabilitation. Thus, early detection of patients at risk of depression is crucial, so effective non-pharmacological strategies can be introduced at its onset to facilitate post-operative rehabilitation and to minimize the risk of developing late life depression $[9,11]$.

The strength of our study is the large sample size, which allowed for the detection of small increases in depressive symptoms with increasing age. There are a number of limitations of this study. Firstly, as the assessments were performed in a sample in a single hospital and patients with advanced dementia or acute delirium with incomplete recovery were excluded, the interpretations have selection bias and may not be necessarily generalized to other patients. Secondly, a cross sectional design did not allow inference of the causes of depression because the data were examined during a single period. Thirdly, the diagnosis of dementia of these patients was often made in another institution and the diagnosis could not be verified during their hip fracture admission. Lastly, the proportion of older patients who had been prescribed anti-depressants was not recorded in the administrative dataset for analysis.

\section{Conclusion}

Depressive symptoms were prevalent after hip fracture. Patients with advancing age and dementia were at higher risk for depressive symptoms. Understanding psychosocial risk factors for patients may help clinicians to identify patients at risk for depression who would benefit from screening and management.

\section{References}

1. Cole MG, Dendukuri N (2003) Risk factors for depression among elderly community subjects: a systematic review and meta-analysis. Am J Psychiatry 160: $1147-1156$.

2. Holmes JD, House AO (2000) Psychiatric illness in hip fracture. Age Ageing 29: $537-546$.

3. Cree M, Soskolne CL, Belseck E, Hornig J, McElhaney JE, et al. (2000) Mortality and institutionalization following hip fracture. J Am Geriatr Soc 48: 283-288.

4. Feng L, Scherer SC, Tan BY, Chan G, Fong NP, et al. (2010) Comorbid cognitive impairment and depression is a significant predictor of poor outcomes in hip fracture rehabilitation. Int Psychogeriatr 22: 246-253.

5. Morghen S, Bellelli G, Manuele S, Guerini F, Frisoni GB, et al. (2010) Moderate to severe depressive symptoms and rehabilitation outcome in older adults with hip fracture. Int J Geriatr Psychiatry 26: 1136-1143.

6. Nightingale S, Holmes J, Mason J, House A (2001) Psychiatric illness and mortality after hip fracture. Lancet 357: 1264-1265

7. Bellelli G, Frisoni GB, Turco R, Trabucchi M (2008) Depressive symptoms combined with dementia affect 12-months survival in elderly patients after rehabilitation post-hip fracture surgery. Int J Geriatr Psychiatry 23: 10731077.

8. Guerini F, Morghen S, Lucchi E, Bellelli G, Trabucchi M (2010) Depressive symptoms and one year mortality among elderly patients discharged from a rehabilitation ward after orthopaedic surgery of the lower limbs. Behav Neurol 23: 117-1121.

9. Lenze EJ, Munin MC, Skidmore ER, Dew MA, Rogers JC, et al. (2007) Onset of depression in elderly persons after hip fracture: implications for prevention and early intervention of late-life depression. J Am Geriatr Soc 55: 81-86.

10. Kennedy GJ, Kelman HR, Thomas C (1990) The emergence of depressive symptoms in late life: the importance of declining health and increasing disability. J Community Health 15: 93-104.

11. Romeo R, Knapp M, Banerjee S, Morris J, Baldwin R, et al. (2011) Treatment and prevention of depression after surgery for hip fracture in older people: cost-effectiveness analysis. J Affect Disord128: 211-219.

12. Robertson BD, Robertson TJ (2006) Postoperative delirium after hip fracture J Bone Joint Surg Am 88: 2060-2068.

13. Mossey JM, Mutran E, Knott K, Craik R (1989) Determinants of recovery 12 months after hip fracture: the importance of psychosocial factors. Am J Public Health 79: 279-286

14. Lieberman D, Galinsky D, Fried V, Grinshpun Y, Mytlis N, et al. (1999) Geriatric Depression Screening Scale (GDS) in patients hospitalized for physical rehabilitation. Int J Geriatr Psychiatry 14: 549-555.

15. Pautex S, Jacques MC, Sant A, Herrmann F, Chevalley T (2005) A short comprehensive assessment to predict outcome of elderly patients after hip fracture. Aging Clin Exp Res 17: 116-120.

16. Brown LM, Schinka JA (2005) Development and initial validation of a 15-item informant version of the Geriatric Depression Scale. Int J Geriatr Psychiatry 20: $911-918$

17. Owens WD, Felts JA, Spitznagel EL Jr (1978) ASA physical status classifications: a study of consistency of ratings. Anesthesiology 49: 2392343.

18. Inouye SK, van Dyck CH, Alessi CA, Balkin S, Siegal AP, et al. (1990) Clarifying confusion: the confusion assessment method. A new method for detection of delirium. Ann Intern Med 113: 941-948.

19. Billig N, Ahmed SW, Kenmore P, Amaral D, Shakhashiri MZ (1986) 
Citation: Lai MM, Mughal N, Fong C, Fenner S. Perioperative Depression in Older Patients after Hip Fracture. J Geriatrics Palliative Care 2013;1(1): 4.

ISSN: 2373-1133

Assessment of depression and cognitive impairment after hip fracture. J Am Geriatr Soc 34: 499-503.

20. Wancata J, Alexandrowicz R, Marquart B, Weiss M, Friedrich F (2006) The criterion validity of the Geriatric Depression Scale: a systematic review. Acta
Psychiatr Scand 114: 398-410.

21. Whyte EM, Mulsant BH (2002) Post stroke depression: epidemiology, pathophysiology, and biological treatment. Biol Psychiatry 52: 253-264. 